OPEN ACCESS

Edited by:

MinJae Lee,

University of Texas Southwestern Medical Center, United States

Reviewed by:

Krushna Chandra Sahoo,

Regional Medical Research Center (ICMR), India

Rinshu Dwivedi,

Indian Institute of Information

Technology Tiruchirappalli, India Minati Sahoo,

Central University of Orissa Koraput, India

*Correspondence: Laurette Dubé

laurette.dube@mcgill.ca

Specialty section:

This article was submitted to Life-Course Epidemiology and Social Inequalities in Health

a section of the journal

Frontiers in Public Health

Received: 15 January 2021

Accepted: 30 March 2021

Published: 21 May 2021

Citation:

Wu Y-H, Moore S, McRae C and Dubé L (2021) Tracing the Single and

Combined Contributions of Home-Grown Supply and Health

Literacy on Fruit and Vegetable

Consumption: An Empirical

Exploration in Rural India.

Front. Public Health 9:591439. doi: 10.3389/fpubh.2021.591439

\section{Tracing the Single and Combined Contributions of Home-Grown Supply and Health Literacy on Fruit and Vegetable Consumption: An Empirical Exploration in Rural India}

\author{
Yun-Hsuan Wu ${ }^{1,2}$, Spencer Moore ${ }^{3}$, Cameron McRae ${ }^{2,4}$ and Laurette Dubée ${ }^{2,4 *}$ \\ ${ }^{1}$ Department of Public Health, China Medical University, Taichung, Taiwan, ${ }^{2}$ McGill Centre for the Convergence of Health and \\ Economics, McGill University, Montreal, QC, Canada, ${ }^{3}$ Health and Society Group, Wageningen University and Research, \\ Wageningen, Netherlands, ${ }^{4}$ Desautels Faculty of Management, McGill University, Montreal, QC, Canada
}

Low fruit and vegetable consumption (FVC) remains a global health challenge. Fostering subsistence agriculture through the production and home-grown consumption (HGC) of fruits and vegetables are seen as potential strategies for improving overall FVC, in particular, for developing countries like India. In addition, educational strategies targeting FVC health literacy are also used. Little evidence has documented a connection between these two strategies. We examine the single and combined influence of HGC and health literacy with regard to benefits from fruits and vegetable consumption. Data were collected from 427 rural households in the state of Odisha, India. Three outcomes were examined: FVC, as well as fruit and vegetables separately. Linear and Poisson regression were used to examine the association among home-grown consumption (HGC), FVC health literacy, and the FVC outcomes. Findings show that HGC, but not FVC health literacy, was directly associated with FVC $(\beta=0.65$, SE $=0.10$, $p=0.008)$ and vegetable consumption $(\beta=0.57$, SE $=0.11, p=0.02)$. However, both HGC ( $\beta=0.58$, SE $=0.05, p<0.01)$ and FVC health literacy $(\beta=-0.07$, SE $=0.02, p=0.001$ ) were associated with fruit consumption. In addition, HGC effect is concentrated among participants who reported low FVC health literacy, especially on overall FVC and vegetables alone. Results are discussed in relation to the beneficial role played by HGC in those particularly vulnerable households who perceived little FVC health literacy. Our results provide insights on novel improved FVC consumption across all population segments. Future research should explore the complex interplay between agricultural policies and educational programs in the design of interventions promoting fruit and vegetable production and consumption.

Keywords: health literacy, agriculture, nutrition, fruits and vegetables, home-grown consumption 


\section{INTRODUCTION}

Fruits and vegetables (FVs) are important components of a healthy diet, and when consumed in sufficient levels, it can reduce the risk of chronic diseases, such as diabetes and obesity, cardiovascular diseases, and certain types of cancer (1-5). The Food and Agriculture Organization of the United Nations/World Health Organization (FAO/WHO) recommends a daily individual intake of at least $400 \mathrm{~g}$ of FVs a day, which is the equivalent of five servings of $80 \mathrm{~g}$ each (6). Yet, in spite of robust evidence for the benefits associated with normative fruit and vegetable consumption (FVC), the majority of people consistently consume less than the daily recommended FV intakes (6-9). In 2017 alone, it is estimated that inadequate fruit and vegetable consumption led to an estimated 3.9 million deaths worldwide (10).

Among people living in low- and middle-income countries (LMICs), $78 \%$ consume less than the daily recommended FVC $(7,8)$. Low FVC has been recognized as a leading dietary risk for LMICs (11), and therefore, its contribution to the global burden of diseases and food insecurity are particularly pressing $(12,13)$. Recently, there has been an increased strategic focus on multisectoral convergence for nutrition-sensitive programs-programs that involve diverse sectors, such as agriculture, education, health, water, and sanitation-in order to affect the underlying determinants of nutritional issues (14-18). One of the key nutrition-sensitive pathways through which agriculture can impact nutrition in developing countries, like India, is food access from homegrown produce $(14,19)$. Home-grown produce may include at-home gardens for average consumers in urban areas (20) or, for farmers in rural areas, only one element of a broader homestead food production system. Agricultural produce from homesteads cannot only be sold to earn income for food expenses but also can be used for people's own household consumption $(19,21,22)$.

Direct linkages between agricultural production and nutrition are created by household decisions regarding the quantity and composition of food production, which are partially reliant on the needs of the household (23). Surendran et al. recently documented home-grown consumption as a key pathway through which peri-urban households in Hyderabad, Telangana (approximately 1,000 km southwest of our study site), sourced food for consumption, with support tied strongest to vegetables that are cultivated more ubiquitously, when compared with fruits, among the farmers they interviewed (24). Studies in developed countries have also supported this farm-level pathway to nutrition, with empirical evidence for adults residing in the United Kingdom (25), as well as children living in the rural United States (26). Despite the intuitive appeal of home-grown consumption (HGC) as means of increasing FVC, there is scant empirical evidence to support these initiatives and a need for

\footnotetext{
Abbreviations: FC, fruit consumption; FVs, fruits and vegetables; FVC, fruit and vegetable consumption; HGC, home-grown consumption; HgFVC, home-grown fruit and vegetable consumption; NSSO, National Sample Survey Office; VC, vegetable consumption.
}

more, and better, research to support program design $(27,28)$. This is in part due to the disconnection between agriculture, nutrition, public health, and economics research, combined with the lack of survey data that links these various fields (23). For instance, information about agricultural production is often missed in nutrition surveys, whereas anthropometric and nutritional measures may be lacking in agricultural and economic surveys (19). Again, in India, a recent exploratory analysis of factors underlying inadequate and unequal fruit and vegetable consumption using National Sample Survey Office (NSSO) data did not measure agricultural production or homegrown consumption within the same study and, therefore, did not identify it as a contributing factor, which again highlights the disconnect among sectors (29).

Beside the agriculture sector, education and knowledge-based interventions targeting behavior change are often used as a means to improve FVC by increasing health literacy, such as nutrition knowledge, nutritional benefits, dietary guidelines, core food group intake, or specific nutrition education to prevent or manage diseases (30). For instance, perceived benefits of eating FVs are associated with actual FVC $(31,32)$. Several components of health literacy are tied to FVC, including disease prevention, health promotion, and general health literacy (33). Maternal health literacy is also associated with early childhood development, where high health literacy has been observed to reduce the likelihood of childhood stunting and underweight among children in rural and urban India (34). Other studies have also documented the association between health literacy and FVC in high-income economies (35-38). Yet, few studies have assessed the relative contribution of agriculture strategies and nutrient health literacy to explain FVC in low-income settings, which is particularly important to know for developing countries and emerging economies where households perceive more barriers toward changing FVC behaviors $(9,39)$. While a recent review of nutrition-sensitive programs led by Ruel et al. suggests that agriculture programs could be more effective at improving maternal and child nutrition outcomes when incorporated with nutrition and health behavior change communications, little empirical evidence exists to support this linkage (40).

India is the second largest agricultural producer of FVs in the world, accounting for roughly 10 and $15 \%$, respectively, of total global production (7). Traditionally, the Indian diet had a strong affinity for FVs. Yet, surveys in India have indicated low levels of FVC $(41,42)$, and a prevalence of low FVC as high as $74 \%$ among adults (8). The most recent research indicates that, according to the nationwide NSSO Household Consumer Expenditure Survey 2011-2012, the per capita household intake are $145 \mathrm{~g}$ for fruits and $15 \mathrm{~g}$ for vegetables per day for rural India, and 155 and $29 \mathrm{~g}$, respectively, for urban India (43). Both rural and urban FVC fall lower than that of the recommended intake value. According to a recent study in rural India (44), home-grown consumption can mediate the influence of farm-level interventions targeted at increasing consumption of FVs. However, FVC is the product of a complex interaction of factors, and only limited studies have assessed the independent and interacting influences of agricultural- and knowledge-based drivers on improving FVC, especially in India. 
Additionally, the drivers of eating behaviors, including food choices and consumption, are the results of the complex interplay among sociodemographic, psychosocial, and environmental factors (45). Therefore, a single-faceted contribution of knowledge or agriculture might be not enough to improve FVC at the recommended levels that it requires (46). A limited number of studies have examined drivers of FVC specifically despite much work being done for food overall, including the impact of availability, accessibility, affordability, appeal, accommodation, and acceptability of consumption [for review, see Caspi et al. (47); French et al. (48); Glanz et al. (49); Dubé et al. (50); Dubé et al. (51); Chandon and Wansink (52)]. As rural areas open to modern agri-food development and urbanization, the expansion of retail marketing is expected to provide a steady, affordable supply of FVs, but evidence also remains limited $(53,54)$.

Although some empirical work from rural India has shown that home-grown fruit and vegetable consumption (HgFVC) can mediate FVC (44), it is not clear whether and how FVC health literacy could modify the association between HgFVC and FVC. Therefore, this study addresses this gap by not only evaluating the relative contributions of $\mathrm{HgFVC}$ and health literacy in rural India but also examining the modifying role of health literacy. In addition, this study further estimates whether the influence of HGC and other drivers on FVC may vary by different levels of health literacy.

\section{METHODS}

\section{Data}

Data were obtained from the baseline survey of an agri-food value chain intervention sponsored by Grand Challenges India (44). The intervention was implemented by eKutir, a social enterprise in the state of Odisha, India, that leverages both information and communication technology (ICT) platform-enabled ecosystem and a micro-entrepreneurial deployment strategy to solve food and nutrition insecurity in low-resource rural communities. eKutir provides inputs, technical assistance, market linkages, and daily market pricing information through ICT tools deployed throughout their ecosystem. The evolution of eKutir's ICTenabled ecosystem (55) as well as its impact on FVC for rural farmers and urban consumers (44) have previously been studied.

The baseline survey for this study was conducted in four districts of rural Odisha: Kandhamal (I and II), Jharsuguda, Angul, and Nayagarh. The surveys were administered between April and May 2015. Study sites were selected based on existing geographical boundaries, eKutir operational requirements, and consumers' and farmers' voluntary willingness to participate in the evaluation of the program. The following criteria were used to identify rural village sites: (i) high farmer density, (ii) procurement logistics, and (iii) the capacity for hosting a VeggieLite center. Within villages, the number of households selected was proportionate to the village population size. A total of 32 villages with 427 households were selected from the four districts for baseline data collection. Structured questionnaires were administered to participating rural households. The questionnaire included specific modules on (1) household demographic information, (2) cropping pattern and agriculture inputs, (3) fruit and vegetable consumption patterns, and (4) household development and poverty index. Ethical approval was obtained from the Research Ethics Board of McGill University. Informed consent was also collected from all participants.

\section{MEASURES}

\section{Main Outcomes}

FVC was based on self-reported information from each rural household. To calculate the overall consumption for FVs, rural households were asked to name the top five vegetables and fruits that they had consumed in the past 7 days, as well as the quantity, source, and amount they purchased vs. what they grew at home. As per India's dietary guidelines, potatoes were included as vegetables in the calculations. The amount of five vegetables consumed per household in the past 7 days was summed to calculate the total grams of vegetables consumed per household. The total grams of vegetables consumed per household was then divided by the household size and 7 days, in order to calculate the average grams of vegetables consumed per person per day. To arrive at the average daily servings of vegetables per person, the average grams of vegetables consumed per person per day was divided by 80 (56). The average daily servings of fruits per person were calculated in the same manner. Overall, daily servings of FVs were the sum of vegetable and fruit servings.

\section{Independent Variables}

To capture a driver from the agricultural sector, we measured households' level of home-grown consumption (HGC) following four steps: (1) For each reported vegetable, we calculated the amount that households consumed in total grams as a function of the amount that the household consumed in the past 7 days multiplied by the percentage reported to have come from homegrown production, (2) we divided the household HGC total by the household size, (3) we divided this total by 80 to get the average daily servings of vegetable per person, and (4) we summed the amount of daily servings for the top five vegetables (or fruits) consumed from home-grown production.

As for measuring the household health literacy, we asked the participants about their beliefs regarding FVs as a proxy. Using a five-point Likert scale from not very important to very important, participants responded to six items asking, "how important they believe vegetables were for." The six items were (1) improving your family health, (2) good health and nutrition, (3) your body, (4) your eyes and bones, (5) providing nutrients that your body needs, and (6) enhancing immunity/body fighting against disease. Due to the medium to high correlation between these items (Pearson correlation coefficient range: 0.39-0.61), a composite health literacy score was constructed by the weighted sum of six items. The weights were the standardized scoring coefficients from the first component of a principal component analysis due to $58 \%$ of the variability accounting for the first component. High internal reliability justified the use of the composite score (Cronbach's alpha $=0.86$ ). In order to further explore the differential influence of homegrown consumption by the extent of health literacy, we stratified our sample into two 
groups based on the median value of the composite fruit and vegetable health literacy score for subpopulation analyses.

To measure household demand drivers, participants were asked how the following factors affected their decision to purchase FVs: (1) affordability, (2) availability, (3) accessibility, (4) proximity (5) taste (6) easiness to prepare/cook (7) knowledge to prepare FVs, and (8) food safety of FVs. Affordability means people can afford to purchase FVs. Availability is defined as the ability to purchase FVs that the household prefers to eat. Accessibility represents the ability to go to a place where fruits and vegetables are sold. Proximity indicates the nearness of store/place where FVs can be purchased. Indicator responses were on a five-point scale to represent the extent of agreement $(1=$ strongly disagree, $2=$ disagree, $3=$ somewhat agree, $4=$ agree, and $5=$ strongly agree).

\section{Control Variables}

Household socio-economic and -demographic characteristics were included as control variables, including area of irrigated land, education level, primary language spoken, social groups, and household food insecurity. The highest level of education completed by the head of household and the area of irrigated land were included as proximal measures for socio-economic status (SES) for this analysis due to the low reliability of self-reported income collected for this study (44). The primary language was classified into one of the four categories: (1) Odia, (2) Sambalpur, (3) Adivashi, and (4) Other. Social group is one of the greatest determinants of health outcomes in India (57), and for this study, social groups were categorized into four groups: (1) general, (2) scheduled caste (SC), (3) scheduled tribe (ST), or (4) other backward caste (OBC). Among the caste systems, scheduled tribes and scheduled castes are the most socially disadvantaged groups in India (57). Household food insecurity was measured using two questions: (1) "During the last year, was there ever no food to eat of any kind in your house because of lack of resources to get food?" and (2) "Is anybody in your household severely undernourished?" If participants responded no to both questions, they were defined as food secure. However, if they answered yes to either one or both, they were defined as food insecure.

\section{Statistical Analyses}

In this study, households were removed if they were missing information on fruit and vegetable consumption, as well as health literacy, yielding a final analytical sample of 421 households. Descriptive analyses for continuous variables were reported with means and standard errors, and categorical variables were reported with percentages for the whole sample. Additional comparisons between low- and high-health literacy groups were assessed using the $t$-test for continuous variables with normal distribution as well as the Wilcoxon Mann-Whitney $U$-test for continuous variables without normal distribution and chi-square test for categorical variables. Using overall FVC as the main outcome, a multivariable regression model was then built to evaluate the association of home-grown fruit and vegetable consumption (HgFVC) and other drivers with $\mathrm{FVC}$ after adjusting all control variables, including eight household demand indicators, area of irrigated land, education, primary language spoken, social group, household food insecurity (Model 1). In Model 2, the interaction term between HgFVC and health literacy was added to Model 1 to examine whether the influence of HgFVC on FVC may vary with health literacy. Following the same modeling process, analyses were conducted separately for average daily servings of (1) vegetables per person and (2) fruits per person. Since the distribution of average daily servings of fruits and vegetables per person, as well as vegetables per person, were close to normal, linear regressions were used for the modeling process. Poisson regression was used for the outcome of average daily servings of fruits per person due to its skewed distribution toward zero servings. Since the interactions between HGC and health literacy for the three outcomes were all significant, subpopulation analyses were conducted to further assess if the influence of HGC and other drivers might differ between the low- and high-health literacy groups. An a priori power calculation shows that based on 15 predictors, and a twosided significance level of $0.05,139$ participants would provide $80 \%$ power to detect a medium effect size $\mathrm{f}^{2}$ of 0.15 by using $G^{*}$ Power 3.1.9.7 software (58). All analyses were conducted in STATA, version 14 (Stata, College Station, TX, USA).

\section{RESULTS}

Descriptive analyses are shown in Table 1. The mean value of daily FV servings per person was $3.35(\mathrm{SD}=1.69)$, with average daily vegetable servings of 3.13 ( $\mathrm{SD}=1.57$ ) per person and average daily fruit servings of $0.22(\mathrm{SD}=0.52)$ per person. Among the participants, $87 \%$ did not reach the recommended levels of five or more servings of fruits and vegetables per day. Specifically, 54\% of participants did not consume three or more servings of vegetables daily per person, only $1 \%$ of participants $(n$ $=5$ ) consumed two or more servings of fruits daily per person, and around $69 \%$ of participants consumed zero servings of fruits daily. When comparing between the low- and high-health literacy groups, there were no differences for overall FVC and vegetable consumption (VC) alone, but the high-health literacy group had significantly lower fruit consumption (FC) compared with the lower one.

The multivariable linear regression results for FVC, VC, and FC are shown in Table 2. The study found that people with a high level of home-grown fruits and vegetables consumption (HgFVC) would associate with more FVC $(\beta=0.65, \mathrm{SE}=0.10, p=$ 0.008 ), but the household health literacy was not associated with $\mathrm{FVC}(\beta=0.12, \mathrm{SE}=0.07, p=0.21)$ after adjusting for control variables. The results also presented the similar findings for $\mathrm{VC}$ where VC positively associated with home-grown VC $(\beta=0.57$, $\mathrm{SE}=0.11, p=0.02)$, but not with health literacy $(\beta=0.15$, SE $=0.07, p=0.11)$. Meanwhile, among the demand indicators, both availability $(\beta=0.29, \mathrm{SE}=0.06, p=0.02)$ and accessibility $(\beta=0.06, \mathrm{SE}=0.01, p=0.02)$ were both positively associated with VC. As for FC, individuals who consumed more homegrown fruits $(\beta=0.58, \mathrm{SE}=0.05, p<0.01)$ also reported higher FC. However, there was an interesting result showing that higher health literacy was specifically associated with less $\mathrm{FC}(\beta=-0.07$, $\mathrm{SE}=0.02, p=0.001)$. When comparing with $\mathrm{VC}$, there were two 
TABLE 1 | Descriptive information for all, low-, and high-health literacy groups.

\begin{tabular}{|c|c|c|c|c|}
\hline & All & Low & High & \\
\hline & Mean (SD) & Mean (SD) & Mean (SD) & $p$-value* \\
\hline \multicolumn{5}{|l|}{ Daily servings per capita } \\
\hline Fruits and vegetables & $3.35(1.69)$ & $3.29(1.72)$ & $3.44(1.64)$ & 0.34 \\
\hline $\begin{array}{l}\text { Fruits and vegetables } \\
\text { consumed from } \\
\text { home-grown }\end{array}$ & $1.01(1.44)$ & $1.19(1.55)$ & $0.80(1.27)$ & $<0.01$ \\
\hline Vegetables & $3.13(1.57)$ & $3.02(1.61)$ & $3.28(1.50)$ & 0.09 \\
\hline $\begin{array}{l}\text { Vegetables consumed } \\
\text { from home-grown }\end{array}$ & $0.93(1.37)$ & $1.10(1.46)$ & $0.73(1.22)$ & $<0.01$ \\
\hline Fruits & $0.22(0.52)$ & $0.27(0.60)$ & $0.16(0.39)$ & 0.04 \\
\hline $\begin{array}{l}\text { Fruits consumed from } \\
\text { home-grown }\end{array}$ & $0.27(0.65)$ & $0.27(0.78)$ & $0.26(0.42)$ & 0.28 \\
\hline \multicolumn{5}{|l|}{ Household demand indicators } \\
\hline Affordability & $3.65(0.73)$ & $3.69(0.70)$ & $3.59(0.78)$ & 0.19 \\
\hline Availability & $3.85(0.70)$ & $3.83(0.63)$ & $3.87(0.78)$ & 0.50 \\
\hline Accessibility & $3.83(0.71)$ & $3.84(0.71)$ & $3.81(0.71)$ & 0.70 \\
\hline $\begin{array}{l}\text { Proximity -the store/place } \\
\text { being near you }\end{array}$ & $2.93(1.16)$ & $2.81(1.10)$ & $3.08(1.22)$ & 0.02 \\
\hline Taste & $4.01(0.49)$ & $3.95(0.43)$ & $4.10(0.55)$ & $<0.01$ \\
\hline Easiness to prepare/cook & $4.15(0.56)$ & $4.07(0.55)$ & $4.26(0.56)$ & $<0.01$ \\
\hline Knowledge to prepare FV & $4.05(0.63)$ & $3.94(0.59)$ & $4.19(0.65)$ & $<0.01$ \\
\hline Food safety of FV & $3.91(0.58)$ & $3.77(0.54)$ & $4.11(0.57)$ & $<0.01$ \\
\hline \multicolumn{5}{|l|}{ Household health literacy } \\
\hline $\begin{array}{l}\text { Composite score from the } \\
\text { principal component } \\
\text { analysis }\end{array}$ & $9.75(1.42)$ & & & \\
\hline $\begin{array}{l}\text { Area of irrigated land } \\
\text { (hectares) }\end{array}$ & $2.31(2.23)$ & $2.19(2.02)$ & $2.47(2.50)$ & 0.21 \\
\hline $\begin{array}{l}\text { The highest level of education } \\
\text { completed by the head of } \\
\text { household (Rank from } 1 \text { to } 8 \text { ) }\end{array}$ & $3.46(1.56)$ & $3.43(1.52)$ & $3.50(1.61)$ & 0.66 \\
\hline Primary language spoken (\%) & & & & $<0.01$ \\
\hline Odia & 44.7 & 52.05 & 34.46 & \\
\hline Sambalpur & 18.1 & 19.26 & 16.38 & \\
\hline Adivashi & 29.7 & 19.67 & 43.5 & \\
\hline Other & 7.6 & 9.02 & 5.65 & \\
\hline Social group (\%) & & & & 0.05 \\
\hline General & 23.8 & 27.46 & 18.64 & \\
\hline Scheduled caste (SC) & 6.7 & 7.79 & 5.08 & \\
\hline Scheduled tribe (ST) & 47.3 & 42.21 & 54.24 & \\
\hline $\begin{array}{l}\text { Other backward caste } \\
\text { (OBC) }\end{array}$ & 22.3 & 22.54 & 22.03 & \\
\hline Household food insecurity (\%) & & & & 0.21 \\
\hline No & 89.9 & 91.8 & 88.14 & \\
\hline Yes & 10.1 & 8.2 & 11.86 & \\
\hline
\end{tabular}

*The $p$-value of statistical comparison between low- and high-health literacy groups.

different demand drivers associated with FC: taste $(\beta=0.32$, SE $=0.11, p=0.005)$ and easiness to prepare $/ \operatorname{cook}(\beta=-0.25$, SE $=0.09, p=0.006$ ).

As shown in Model 2 on Table 2, the interaction between household health literacy and HGC was significant for each outcome measure: FVC $(\beta=-0.09, \mathrm{SE}=0.02, p=0.02)$, VC $(\beta=-0.09, \mathrm{SE}=0.02, p=0.01)$, and $\mathrm{FC}(\beta=0.17, \mathrm{SE}=$ $0.08, p=0.03)$. According to the subpopulation analyses, HGC was positively associated with overall $\mathrm{FVC}(\beta=0.75, \mathrm{SE}=0.12$, $p=0.008)$ and VC $(\beta=0.69, \mathrm{SE}=0.12, p=0.01)$ among those who had little health literacy, but not among those who perceived more health literacy (FVC: $\beta=0.33, \mathrm{SE}=0.11, p=0.06$; VC: $\beta=0.26, \mathrm{SE}=0.09, p=0.06$ ) (Tables 3,4$)$. In contrast, people with more home-grown FC consume more fruits among both the low- and high-health literacy groups (low: $\beta=0.56, \mathrm{SE}=0.08$, $p=<0.01$; high: $\beta=0.77$, SE $=0.08, p=<0.01$ ) (Table 5). Additionally, among the low- and high-health literacy groups, differential demand drivers may have diverse influence on FVC. For instance, more knowledge to prepare FVs could increase $\mathrm{VC}$ in the low-health literacy group but reduce VC in the high one. Only easiness to prepare/cook was negatively associated with FC in the low-health literacy group. However, among the highhealth literacy group, we found that affordability and easiness to prepare/cook had positive influence, but accessibility and knowledge to prepare FVs had negative influence on FC.

\section{DISCUSSION}

This research examined the single and combined contributions of home-grown consumption (HGC) and FVC health literacy in rural India. The evidence from the current study indicates that higher HGC is associated with higher consumption of fruits and vegetables, which confirms previous evidence on the efficacy of agricultural approaches as a way of increasing FVC by promoting $\operatorname{HGC}(17,19,21,22)$. Previous research suggested that home-grown agriculture can influence food choices (59), as well as dietary diversity (60), and that it could be one aspect of agricultural strategies to combat low FVC. The mechanism through which this pathway operates is that home-grown production is expected to provide a direct resource of food to be eaten by a household, especially in the context where food marketing cannot function properly (60).

Evidence has shown that homestead farming contributes significantly to nutrition outcomes in developing countries ( 7 , 61). For example, one recent review demonstrates an association between agricultural interventions and nutritional outcomes in South Asia and indicated that homestead gardens could play a crucial role in increasing the consumption of FVs (22). In addition, the results from the study in rural Andhra Pradesh, India, showed that after introducing homestead gardens, households increased the frequency of green leafy vegetable consumption (62). Encouraging home-grown agriculture may not only increase access to fresh FVs for producers and their families but also provide financial savings of purchasing FVs (63), which are part of hypothesized factors contributing to access and affordability for FVs $(64,65)$. India is one of the largest global producers of FVs, but the majority of production is exported (66). However, food intake of agricultural households still largely depends on farmers' own production in India $(22,67)$, and evidence has also shown that home-grown agriculture may result in an increased intake of FVs (68). Existing agricultural policy in India mainly focuses on growing government support 
TABLE 2 | Multivariable model analyses for daily servings per capita of fruits and vegetables, vegetables only, and fruits only.

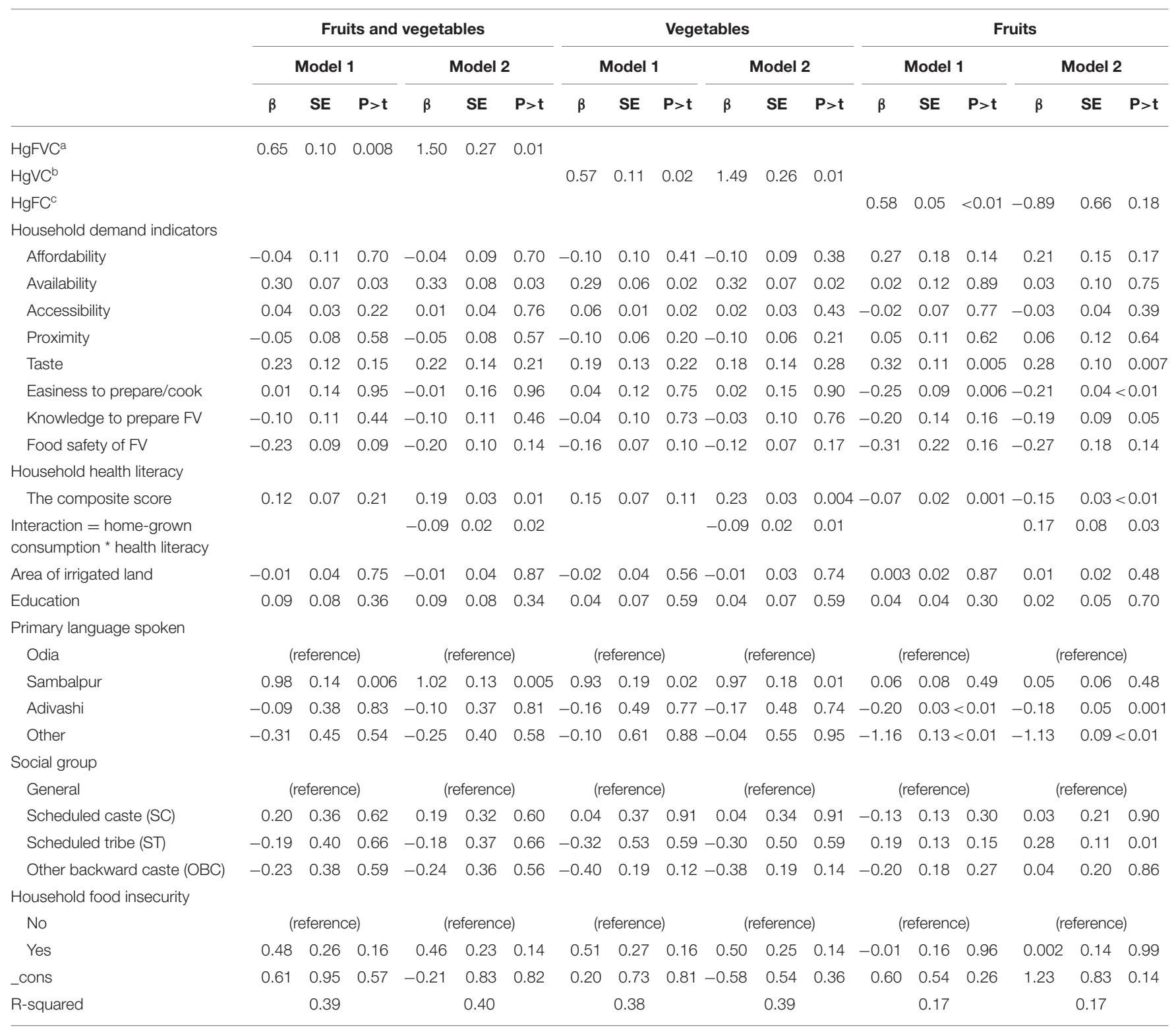

${ }^{a} \mathrm{HgFVC}$, the servings of fruits and vegetables consumed per capita per day from home-grown.

${ }^{b} \mathrm{HgVC}$, the servings of vegetables consumed per capita per day from home-grown.

${ }^{c} \mathrm{HgFC}$, the servings of fruits consumed per capita per day from home-grown.

for increasing FV production, infrastructure development, and agricultural marketing (66). Yet, our results also point to the need for agricultural policies and programs that promote home-grown agriculture as a means to improve FVC.

Previous studies have treated fruits and vegetables in a similar manner when exploring the drivers of FVC. However, recent studies argue that fruits should be considered separately from vegetables given that drivers could be different, and separate strategies may be needed (69-71). Our study has shown that there were differential drivers for fruit and vegetable consumption, which is consistent with previous findings $(45,69,71-74)$. In this study, people's perceptions of the availability and accessibility of fruits and vegetables were associated with vegetable, but not fruit, consumption. In India, there are few local markets in rural areas and, thus, more restrictions in the variety of FVs available for purchase $(53,54)$. Since vegetables are generally less expensive and affordable $(75,76)$, availability and accessibility may play even more essential roles in encouraging vegetable consumption in India. Fruit consumption was positively associated with taste, but negatively associated with easiness to prepare/cook and health literacy. In eastern cultures, such as India, people believe that foods that are pleasant and fresh in taste could promote health, physical strength, and mental abilities (77, 78), and this belief may result in increasing consumption of food with 
TABLE 3 | Subpopulation analyses for the servings of fruits and vegetables consumed per capita per day by high-/low-health literacy groups.

\begin{tabular}{|c|c|c|c|c|c|c|}
\hline & \multicolumn{3}{|c|}{$\begin{array}{c}\text { Low health literacy } \\
\text { group }\end{array}$} & \multicolumn{3}{|c|}{$\begin{array}{c}\text { High health literacy } \\
\text { group }\end{array}$} \\
\hline & $\beta$ & SE & $P>t$ & $\beta$ & SE & $P>t$ \\
\hline $\mathrm{HgFVC}^{\mathrm{a}}$ & 0.75 & 0.12 & 0.008 & 0.33 & 0.11 & 0.06 \\
\hline \multicolumn{7}{|l|}{ Household demand indicators } \\
\hline Affordability & -0.11 & 0.11 & 0.38 & 0.12 & 0.24 & 0.67 \\
\hline Availability & 0.25 & 0.13 & 0.15 & 0.13 & 0.12 & 0.36 \\
\hline Accessibility & 0.10 & 0.16 & 0.58 & 0.17 & 0.25 & 0.54 \\
\hline $\begin{array}{l}\text { Proximity - the store/place } \\
\text { being near you }\end{array}$ & -0.01 & 0.17 & 0.94 & -0.05 & 0.05 & 0.36 \\
\hline Taste & 0.40 & 0.17 & 0.09 & 0.02 & 0.17 & 0.91 \\
\hline Easiness to prepare/cook & -0.15 & 0.19 & 0.49 & -0.11 & 0.15 & 0.50 \\
\hline Knowledge to prepare FV & 0.21 & 0.08 & 0.08 & -0.42 & 0.08 & 0.01 \\
\hline Food safety of FV & -0.37 & 0.26 & 0.25 & 0.02 & 0.11 & 0.85 \\
\hline Area of irrigated land & -0.01 & 0.03 & 0.75 & 0.01 & 0.03 & 0.69 \\
\hline Education & 0.05 & 0.04 & 0.32 & 0.09 & 0.08 & 0.37 \\
\hline \multicolumn{7}{|l|}{ Primary language spoken } \\
\hline Odia & \multicolumn{3}{|c|}{ (reference) } & \multicolumn{3}{|c|}{ (reference) } \\
\hline Sambalpur & 0.37 & 0.09 & 0.03 & 1.85 & 0.13 & 0.001 \\
\hline Adivashi & 0.27 & 0.05 & 0.01 & -0.98 & 0.25 & 0.03 \\
\hline Other & -0.44 & 0.09 & 0.02 & -0.65 & 0.24 & 0.07 \\
\hline \multicolumn{7}{|l|}{ Social group } \\
\hline General & \multicolumn{3}{|c|}{ (reference) } & \multicolumn{3}{|c|}{ (reference) } \\
\hline Scheduled caste (SC) & 0.01 & 0.39 & 0.99 & 0.42 & 0.41 & 0.39 \\
\hline Scheduled tribe (ST) & -0.29 & 0.18 & 0.20 & 0.41 & 0.30 & 0.26 \\
\hline $\begin{array}{l}\text { Other backward caste } \\
\text { (OBC) }\end{array}$ & -0.19 & 0.55 & 0.76 & -0.29 & 0.11 & 0.08 \\
\hline \multicolumn{7}{|l|}{ Household food insecurity } \\
\hline No & \multicolumn{3}{|c|}{ (reference) } & \multicolumn{3}{|c|}{ (reference) } \\
\hline Yes & 0.38 & 0.51 & 0.51 & -0.37 & 0.19 & 0.14 \\
\hline _cons & 1.06 & 0.90 & 0.32 & 3.54 & 0.89 & 0.03 \\
\hline R-squared & \multicolumn{3}{|c|}{0.51} & \multicolumn{3}{|c|}{0.44} \\
\hline
\end{tabular}

${ }^{a} \mathrm{HgFVC}$, the servings of fruits and vegetables consumed per capita per day from homegrown.

good taste, such as fruits. There was an interesting finding on the negative association between easiness to prepare/cook and FC, which was inconsistent with previous research (70) and requires further study. Generally, people would increase their fruit consumption once the health benefits of fruits are known $(31,72)$. Perhaps, farmers who know this fact may choose to sell the majority of the fruits they grow due to their high agricultural revenues (79).

Meanwhile, our findings additionally showed that health literacy could modify the influence of HGC on FVC. Specifically, after stratifying the data into low- and high-health literacy groups, the positive influence of HGC on FVC was demonstrated only in the low-health literacy group. Previous evidence suggests that health literacy is a prominent predictor of $\operatorname{FVC}(30,35)$, and for certain nutritional outcomes, nutritional literacy is of paramount importance, while agricultural practices might be less influential (21). Therefore, the potential explanation for our
TABLE 4 | Subpopulation analyses for the servings of vegetables consumed per capita per day by high-/low-health literacy groups.

\begin{tabular}{|c|c|c|c|c|c|c|}
\hline & \multicolumn{3}{|c|}{$\begin{array}{c}\text { Low health literacy } \\
\text { group }\end{array}$} & \multicolumn{3}{|c|}{$\begin{array}{c}\text { High health literacy } \\
\text { group }\end{array}$} \\
\hline & $\beta$ & SE & $P>t$ & $\beta$ & SE & $P>t$ \\
\hline $\mathrm{HgVC}^{\mathrm{a}}$ & 0.69 & 0.12 & 0.01 & 0.26 & 0.09 & 0.06 \\
\hline \multicolumn{7}{|l|}{ Household demand indicators } \\
\hline Affordability & -0.15 & 0.09 & 0.18 & 0.06 & 0.28 & 0.83 \\
\hline Availability & 0.26 & 0.09 & 0.06 & 0.11 & 0.11 & 0.39 \\
\hline Accessibility & 0.07 & 0.17 & 0.73 & 0.19 & 0.26 & 0.53 \\
\hline $\begin{array}{l}\text { Proximity - the store/place } \\
\text { being near you }\end{array}$ & -0.08 & 0.12 & 0.57 & -0.06 & 0.04 & 0.26 \\
\hline Taste & 0.38 & 0.15 & 0.08 & -0.004 & 0.13 & 0.98 \\
\hline Easiness to prepare/cook & -0.11 & 0.21 & 0.64 & -0.21 & 0.17 & 0.30 \\
\hline Knowledge to prepare FV & 0.24 & 0.05 & 0.02 & -0.33 & 0.10 & 0.05 \\
\hline Food safety of FV & -0.23 & 0.20 & 0.34 & 0.09 & 0.11 & 0.50 \\
\hline Area of irrigated land & -0.04 & 0.04 & 0.38 & 0.03 & 0.02 & 0.19 \\
\hline Education & 0.01 & 0.03 & 0.83 & 0.04 & 0.06 & 0.57 \\
\hline \multicolumn{7}{|l|}{ Primary language spoken } \\
\hline Odia & \multicolumn{3}{|c|}{ (reference) } & \multicolumn{3}{|c|}{ (reference) } \\
\hline Sambalpur & 0.45 & 0.04 & 0.002 & 1.61 & 0.10 & 0.001 \\
\hline Adivashi & 0.14 & 0.19 & 0.51 & -1.17 & 0.31 & 0.03 \\
\hline Other & -0.16 & 0.18 & 0.44 & -0.71 & 0.29 & 0.09 \\
\hline \multicolumn{7}{|l|}{ Social group } \\
\hline General & \multicolumn{3}{|c|}{ (reference) } & \multicolumn{3}{|c|}{ (reference) } \\
\hline Scheduled caste (SC) & -0.18 & 0.30 & 0.60 & 0.44 & 0.43 & 0.38 \\
\hline Scheduled tribe (ST) & -0.41 & 0.13 & 0.05 & 0.51 & 0.30 & 0.19 \\
\hline $\begin{array}{l}\text { Other backward caste } \\
\text { (OBC) }\end{array}$ & -0.38 & 0.32 & 0.31 & -0.29 & 0.14 & 0.13 \\
\hline \multicolumn{7}{|l|}{ Household food insecurity } \\
\hline No & \multicolumn{3}{|c|}{ (reference) } & \multicolumn{3}{|c|}{ (reference) } \\
\hline Yes & 0.45 & 0.52 & 0.45 & -0.26 & 0.17 & 0.22 \\
\hline _cons & 0.84 & 1.06 & 0.48 & 3.75 & 0.99 & 0.03 \\
\hline R-squared & \multicolumn{3}{|c|}{0.51} & \multicolumn{3}{|c|}{0.42} \\
\hline
\end{tabular}

${ }^{a} \mathrm{HgVC}$, the servings of vegetables consumed per capita per day from home-grown.

finding is that people with high-health literacy not only have a higher level of their FVC but also would be more aware of whether they could get the sufficient FVC through multiple sources besides home-grown produce $(31,71)$. Based on the descriptive statistics in our study (Table 1), people in the highhealth literacy group did have higher consumption of fruits and vegetables compared with those in the low group. Yet, the intake level of HgFVC is lower in the high-health literacy group than in the low one. It may be argued that people who have sufficient health literacy on FVs find diverse food sources to consume more fruits and vegetables, instead of limiting themselves to access home-grown FVs, and therefore, HGC might not be directly associated with FVC, whereas, for people who have lower levels of health literacy related to fruits and vegetables, may just consume what they produce. Future research is needed to further confirm this argument. 
TABLE 5 | Subpopulation analyses for the servings of fruits consumed per capita per day by high-/low-health literacy groups.

\begin{tabular}{|c|c|c|c|c|c|c|}
\hline & \multicolumn{3}{|c|}{$\begin{array}{c}\text { Low health literacy } \\
\text { group }\end{array}$} & \multicolumn{3}{|c|}{$\begin{array}{c}\text { High health literacy } \\
\text { group }\end{array}$} \\
\hline & $\beta$ & SE & $P>t$ & $\beta$ & SE & $\mathbf{P}>\mathbf{t}$ \\
\hline $\mathrm{HgFC}^{\mathrm{a}}$ & 0.56 & 0.08 & $<0.01$ & 0.77 & 0.08 & $<0.01$ \\
\hline \multicolumn{7}{|l|}{ Household demand indicators } \\
\hline Affordability & 0.22 & 0.23 & 0.33 & 0.10 & 0.02 & $<0.01$ \\
\hline Availability & -0.06 & 0.19 & 0.76 & 0.08 & 0.12 & 0.51 \\
\hline Accessibility & 0.10 & 0.18 & 0.56 & -0.31 & 0.10 & 0.002 \\
\hline $\begin{array}{l}\text { Proximity - the store/place } \\
\text { being near you }\end{array}$ & 0.07 & 0.16 & 0.68 & -0.10 & 0.11 & 0.35 \\
\hline Taste & 0.31 & 0.36 & 0.38 & 0.17 & 0.26 & 0.51 \\
\hline Easiness to prepare/cook & -0.28 & 0.07 & $<0.01$ & 0.22 & 0.09 & 0.02 \\
\hline Knowledge to prepare FV & -0.14 & 0.15 & 0.35 & -0.59 & 0.22 & 0.007 \\
\hline Food safety of FV & -0.44 & 0.20 & 0.03 & -0.26 & 0.27 & 0.35 \\
\hline Area of irrigated land & 0.03 & 0.05 & 0.60 & -0.01 & 0.05 & 0.88 \\
\hline Education & 0.01 & 0.09 & 0.87 & 0.03 & 0.02 & 0.05 \\
\hline \multicolumn{7}{|l|}{ Primary language spoken } \\
\hline Odia & \multicolumn{3}{|c|}{ (reference) } & \multicolumn{3}{|c|}{ (reference) } \\
\hline Sambalpur & -0.11 & 0.20 & 0.58 & 0.08 & 0.19 & 0.67 \\
\hline Adivashi & -0.09 & 0.17 & 0.59 & -0.02 & 0.20 & 0.93 \\
\hline Other & -0.87 & 0.75 & 0.24 & . & . & . \\
\hline \multicolumn{7}{|l|}{ Social group } \\
\hline General & \multicolumn{3}{|c|}{ (reference) } & \multicolumn{3}{|c|}{ (reference) } \\
\hline Scheduled caste (SC) & -0.09 & 0.38 & 0.81 & -0.07 & 0.51 & 0.90 \\
\hline Scheduled tribe (ST) & 0.02 & 0.28 & 0.95 & -0.20 & 0.25 & 0.42 \\
\hline $\begin{array}{l}\text { Other backward caste } \\
\text { (OBC) }\end{array}$ & -0.22 & 0.25 & 0.38 & -0.09 & 0.04 & 0.009 \\
\hline \multicolumn{7}{|l|}{ Household food insecurity } \\
\hline No & \multicolumn{3}{|c|}{ (reference) } & \multicolumn{3}{|c|}{ (reference) } \\
\hline Yes & -0.17 & 0.05 & 0.002 & -0.61 & 0.10 & $<0.01$ \\
\hline _cons & 0.42 & 1.31 & 0.75 & 2.06 & 0.58 & $<0.01$ \\
\hline R-squared & \multicolumn{3}{|c|}{0.19} & \multicolumn{3}{|c|}{0.14} \\
\hline
\end{tabular}

${ }^{a} \mathrm{HgFC}$, the servings of vegetables consumed per capita per day from home-grown.

Meanwhile, the findings also suggest that more vegetable consumption from home grown could increase overall vegetable consumption only among people with low-health literacy. However, the positive impact of home-gown fruit consumption on overall fruit consumption was the same in both lowand high-health literacy groups. Additionally, subpopulation analyses also reveal that differential drivers could be found based on the level of health literacy. These results suggest that when designing an intervention for improving FVC, it would be important to consider differential levels of health literacy among people in order to apply the most appropriate behavioral interventions. For example, knowledge to prepare FVs could have reverse influence on vegetable consumption among low- and high-health literacy groups, and the influence of affordability, accessibility, or knowledge to prepare FVs could be found only in the high-health literacy groups. Different demand drivers in low- and high-health literacy groups may cause different consumption rates of fruits and vegetables among the two groups, as also evidenced by previous studies demonstrating that the determinants of fruit consumption differ from vegetable consumption $(45,69,71-$ 74). For vegetables, people among the high-health literacy group may try to find the various types of vegetables that meet their demand, and the food source would not be limited from their own agricultural produce. However, fruits are generally more expensive than vegetables and other common foods $(75,80)$. Therefore, people among both low- or high-health literacy groups may only consume fruits from their homestead as a more affordable approach.

This study has several limitations. First, the results may not be generalizable to other rural settings since the data were collected in only four districts of rural Odisha. Nevertheless, our main findings of differential drivers and consumption motives that differ by fruit and vegetable consumption literacy level have added further knowledge to fruit and vegetable research. Second, measures of fruit and vegetable consumption, as well as health literacy, are partial. FVC is the most obvious one because no instrument has perfectly captured consumption data-and there are often biases when using self-reported measures. Meanwhile, the measure for health literacy had a similar measurement issue. There are various aspects for health literacy, but the focus of the present study was on perceived health benefit on vegetables due to the limitation on the questionnaire. Third, the data in this study were cross-sectional, and causality should not be directly inferred from the findings in this study.

\section{CONCLUSION}

In India, low consumption of fruits and vegetables undoubtedly constitutes one of the country's critical nutritional problems. Although there is an important role for the agricultural and educational sectors in improving FVC, less is known about their direct and indirect relationships to farmers' decisions about fruit and vegetable consumption. This study filled in the gap of the empirical evidence on the potential contribution of agricultural approaches on FVC, as well as the connection between agricultural and knowledge-based approaches. Results indicated that higher home-grown consumption was associated with improving FVC, with one implication being the importance of agricultural programs as representing viable entry points for increasing FVC. Evidence on the contingent relationship between agricultural and knowledge-based programs highlights the multifaceted approaches needed to promote FVC. Therefore, for countries like India, the policy focusing on behavior or educational approach to increasing FVC was not enough, and the effective policy development need to additionally incorporate agriculture aspect, such as home gardening, to construct stronger synergies to act on nutrition-sensitivity agriculture intervention. In addition, further research on elaborating a clear direction of impact pathways, theories of change, or cost effectiveness of nutrition-sensitivity agriculture intervention is needed in order to translate and provide solid evidence to policy makers. 


\section{DATA AVAILABILITY STATEMENT}

The raw data supporting the conclusions of this article will be made available by the authors, without undue reservation.

\section{ETHICS STATEMENT}

The studies involving human participants were reviewed and approved by Research Ethics Board of McGill University. The patients/participants provided their written informed consent to participate in this study.

\section{AUTHOR CONTRIBUTIONS}

Y-HW was a contributor to the study conception, design, data analysis, and wrote the manuscript. CM contributed toward manuscript preparation and revisions. SM and LD contributed

\section{REFERENCES}

1. Wang X, Ouyang Y, Liu J, Zhu M, Zhao G, Bao W, et al. Fruit and vegetable consumption and mortality from all causes, cardiovascular disease, and cancer: systematic review and dose-response meta-analysis of prospective cohort studies. BMJ. (2014) 349:g4490. doi: 10.1136/bmj.g4490

2. Oyebode O, Gordon-Dseagu V, Walker A, Mindell JS. Fruit and vegetable consumption and all-cause, cancer and CVD mortality: analysis of Health Survey for England data. J Epidemiol Community Health. (2014) 68:856-62. doi: 10.1136/jech-2013-203500

3. Aune D, Giovannucci E, Boffetta P, Fadnes LT, Keum N, Norat T, et al. Fruit and vegetable intake and the risk of cardiovascular disease, total cancer and all-cause mortality-a systematic review and dose-response meta-analysis of prospective studies. Int J Epidemiol. (2017) 46:1029-56. doi: 10.1093/ije/dyw319

4. Bradbury KE, Appleby PN, Key TJ. Fruit, vegetable, and fiber intake in relation to cancer risk: findings from the European Prospective Investigation into Cancer and Nutrition (EPIC)-. Am J Clin Nutr. (2014) 100:394S-8S. doi: $10.3945 /$ ajcn.113.071357

5. Wu Y, Zhang D, Jiang X, Jiang W. Fruit and vegetable consumption and risk of type 2 diabetes mellitus: a dose-response meta-analysis of prospective cohort studies. Nutr Metab Cardiovasc Dis. (2015) 25:140-7. doi: 10.1016/j.numecd.2014.10.004

6. World Health Organization. Diet, nutrition, and the prevention of chronic diseases: report of a joint WHO/FAO expert consultation: World Health Organization (2003).

7. Sachdeva S, Sachdev TR, Sachdeva R. Increasing fruit and vegetable consumption: challenges and opportunities. Indian J Community Med. (2013) 38:192-7. doi: 10.4103/0970-0218.120146

8. Hall JN, Moore S, Harper SB, Lynch JW. Global variability in fruit and vegetable consumption. Am J Prev Med. (2009) 36:402-9. e5. doi: 10.1016/j.amepre.2009.01.029

9. Miller V, Yusuf S, Chow CK, Dehghan M, Corsi DJ, Lock K, et al. Availability, affordability, and consumption of fruits and vegetables in 18 countries across income levels: findings from the Prospective Urban Rural Epidemiology (PURE) study. Lancet Global Health. (2016) 4:e695-e703. doi: 10.1016/S2214-109X(16)30186-3

10. Global Burden of Disease Collaborative Network. Global Burden of Disease Study 2017 (GBD 2017) Results. Seattle, United States: Institute for Health Metrics and Evaluation (IHME) (2018).

11. Afshin A, Sur PJ, Fay KA, Cornaby L, Ferrara G, Salama JS, et al. Health effects of dietary risks in 195 countries, 1990-2017: a systematic analysis for the Global Burden of Disease Study 2017. Lancet. (2019) 393:1958-72. doi: 10.1016/S0140-6736(19)30041-8 toward study conception, design, and data collection. All authors critically reviewed and approved the final manuscript for submission.

\section{FUNDING}

This work was primarily supported by Grand Challenges India sponsored by the Biotechnology Industry Research Assistance Council (BIRAC) (Grant No. BIRAC/GCI/0013/01/13AGN, 2014). Complementary funding came from CGIAR Fund through CGIAR Research Program on Agriculture for Nutrition and Health, the International Development Research Center (IDRC) (Grant No. 107400-006, 2015), Fonds de recherche du Québec-Société et culture (FRQSC) (Grant No. 2015-SE-179342, 2014), and Social Sciences and Humanities Research Council (SSHRC) (Grant No. 410-2010-2258, 2010).

12. Forouzanfar MH, Afshin A, Alexander LT, Anderson HR, Bhutta ZA, Biryukov S, et al. Global, regional, and national comparative risk assessment of 79 behavioural, environmental and occupational, and metabolic risks or clusters of risks, 1990-2015: a systematic analysis for the Global Burden of Disease Study 2015. Lancet. (2016) 388:1659-724. doi: 10.1016/S0140-6736(18)32225-6

13. Feigin VL, Roth GA, Naghavi M, Parmar P, Krishnamurthi R, Chugh S, et al. Global burden of stroke and risk factors in 188 countries, during 1990-2013: a systematic analysis for the Global Burden of Disease Study 2013. Lancet Neurol. (2016) 15:913-24. doi: 10.1016/S1474-4422(16)30073-4

14. Ruel MT, Alderman H, Maternal, Group CNS. Nutrition-sensitive interventions and programmes: how can they help to accelerate progress in improving maternal and child nutrition? Lancet. (2013) 382:536-51. doi: 10.1016/S0140-6736(13)60843-0

15. Headey DD. Developmental drivers of nutritional change: a cross-country analysis. World Dev. (2013) 42:76-88. doi: 10.1016/j.worlddev.2012.07.002

16. Rajpal S, Joe W, Kim R, Kumar A, Subramanian SV. Child undernutrition and convergence of multisectoral interventions in india: an econometric analysis of National Family Health Survey 2015-16. Front Public Health. (2020) 8:129. doi: 10.3389/fpubh.2020.00129

17. Reinhardt K, Fanzo J. Addressing chronic malnutrition through multisectoral, sustainable approaches: a review of the causes and consequences. Front Nutr. (2014) 1:13. doi: 10.3389/fnut.2014.00013

18. Nair MK, Augustine LF, Konapur A. Food-based interventions to modify diet quality and diversity to address multiple micronutrient deficiency. Front Public Health. (2016) 3:277. doi: 10.3389/fpubh.2015.00277

19. Headey D, Chiu A, Kadiyala S. Agriculture's role in the Indian enigma: help or hindrance to the crisis of undernutrition? Food Security. (2012) 4:87-102. doi: 10.1007/s12571-011-0161-0

20. Phulkerd S, Thapsuwan S, Soottipong Gray R, Chamratrithirong A. Characterizing urban home gardening and associated factors to shape fruit and vegetable consumption among non-farmers in Thailand. Int J Environ Res Public Health. (2020) 17:5400. doi: 10.3390/ijerph17155400

21. Kadiyala S, Harris J, Headey D, Yosef S, Gillespie S. Agriculture and nutrition in India: mapping evidence to pathways. Annals N Y Acad Sci. (2014) 1331:4356. doi: 10.1111/nyas. 12477

22. Pandey VL, Dev SM, Jayachandran U. Impact of agricultural interventions on the nutritional status in South Asia: a review. Food Policy. (2016) 62:28-40. doi: 10.1016/j.foodpol.2016.05.002

23. Carletto G, Ruel M, Winters P, Zezza A. Farm-level pathways to improved nutritional status: introduction to the Special Issue. J Dev Stud. (2015) 51:2015-12-24. doi: 10.1080/00220388.2015.1018908

24. Surendran S, Selvaraj K, Turner C, Addanki S, Kannuri NK, Debbarma A, et al. Characterising the fruit and vegetable environment of peri-urban Hyderabad, 
India. Global Food Security. (2020) 24:100343. doi: 10.1016/j.gfs.2019. 100343

25. Billson H, Pryer JA, Nichols R. Variation in fruit and vegetable consumption among adults in Britain. An analysis from the dietary and nutritional survey of British adults. Eur J Clin Nutr. (1999) 53:946-52. doi: 10.1038/sj.ejcn.1600877

26. Nanney MS, Johnson S, Elliott M, Haire-Joshu D. Frequency of eating homegrown produce is associated with higher intake among parents and their preschool-aged children in rural Missouri. J Am Dietetic Assoc. (2007) 107:577-84. doi: 10.1016/j.jada.2007.01.009

27. Girard AW, Self JL, McAuliffe C, Olude O. The effects of household food production strategies on the health and nutrition outcomes of women and young children: a systematic review. Paediatr Perinat Epidemiol. (2012) 26:205-22. doi: 10.1111/j.1365-3016.2012.01282.x

28. Masset E, Haddad L, Cornelius A, Isaza-Castro J. Effectiveness of agricultural interventions that aim to improve nutritional status of children: systematic review. BMJ. (2012) 344:d8222. doi: 10.1136/bmj.d8222

29. Choudhury S, Shankar B, Aleksandrowicz L, Tak M, Green R, Harris F, et al. What underlies inadequate and unequal fruit and vegetable consumption in India? An exploratory analysis. Global Food Security. (2020) 24:100332. doi: 10.1016/j.gfs.2019.100332

30. Spronk I, Kullen C, Burdon C, O'Connor H. Relationship between nutrition knowledge and dietary intake. Br J Nutr. (2014) 111:1713-26. doi: $10.1017 /$ S0007114514000087

31. Steptoe A, Perkins-Porras L, Rink E, Hilton S, Cappuccio FP. Psychological and social predictors of changes in fruit and vegetable consumption over 12 months following behavioral and nutrition education counseling. Health Psychol. (2004) 23:574. doi: 10.1037/0278-6133.23.6.574

32. Shaikh AR, Yaroch AL, Nebeling L, Yeh M-C, Resnicow K. Psychosocial predictors of fruit and vegetable consumption in adults: a review of the literature. Am J Preventive Med. (2008) 34:535-43.e11. doi: $10.1016 /$ j.amepre.2007.12.028

33. Oberne A, Vamos C, Wright L, Wang W, Daley E. Does health literacy affect fruit and vegetable consumption? An assessment of the relationship between health literacy and dietary practices among college students. J Am College Health. (2020). doi: 10.1080/07448481.2020.1727911. [Epub ahead of print].

34. Johri M, Subramanian S, Kone GK, Dudeja S, Chandra D, Minoyan N, et al. Maternal health literacy is associated with early childhood nutritional status in India. J Nutr. (2016) 146:1402-10. doi: 10.3945/jn.115.226290

35. Lim S, Beauchamp A, Dodson S, O'Hara J, McPhee C, Fulton A, et al. Health literacy and fruit and vegetable intake in rural Australia. Public Health Nutr. (2017) 20:2680-4. doi: 10.1017/S1368980017001483

36. Geboers B, de Winter AF, Luten KA, Jansen CJ, Reijneveld SA. The association of health literacy with physical activity and nutritional behavior in older adults, and its social cognitive mediators. J Health Commun. (2014) 19:61-76. doi: $10.1080 / 10810730.2014 .934933$

37. Guntzviller LM, King AJ, Jensen JD, Davis LA. Self-efficacy, health literacy, and nutrition and exercise behaviors in a low-income, Hispanic population. J immigr Minor Health. (2017) 19:489-93. doi: 10.1007/s10903-0160384-4

38. Von Wagner C, Knight K, Steptoe A, Wardle J. Functional health literacy and health-promoting behaviour in a national sample of British adults. J Epidemiol Community Health. (2007) 61:1086-90. doi: 10.1136/jech.2006.053967

39. Pomerleau J, Lock K, Knai C, McKee M. Interventions designed to increase adult fruit and vegetable intake can be effective: a systematic review of the literature. J Nutr. (2005) 135:2486-95. doi: 10.1093/jn/135.10.2486

40. Ruel MT, Quisumbing AR, Balagamwala M. Nutrition-sensitive agriculture: what have we learned so far? Global Food Security. (2018) 17:128-53. doi: 10.1016/j.gfs.2018.01.002

41. National Sample Survey Office (NSSO), Ministry of Statistics and Programme Implementation. Household consumption of various goods and services in India: 66th Round (2009-10). New Delhi: National Sample Survey Office (NSSO), Ministry of Statistics and Programme Implementation, Government of India (2012).

42. Surabhi M. Can Horticulture Be a Success Story for India? New Delhi: Indian Council for Research on International Economic Relations. (2007).

43. Minocha S, Thomas T, Kurpad AV. Are 'fruits and vegetables' intake really what they seem in India? European Journal of Clinical Nutrition. (2018) 72:603-8. doi: 10.1038/s41430-018-0094-1
44. Dubé L, McRae C, Wu Y-H, Ghosh S, Allen S, Ross D, et al. Impact of the eKutir ICT-enabled social enterprise and its distributed micro-entrepreneur strategy on fruit and vegetable consumption: a quasi-experimental study in rural and urban communities in Odisha, India. Food Policy. (2020) 90:101787. doi: 10.1016/j.foodpol.2019.101787

45. Trudeau E, Kristal AR, Li S, Patterson RE. Demographic and psychosocial predictors of fruit and vegetable intakes differ: implications for dietary interventions. J Am Dietetic Assoc. (1998) 98:1412-7. doi: 10.1016/S0002-8223(98)00319-8

46. Dhandevi P, Jeewon R. Fruit and vegetable intake: benefits and progress of nutrition education interventions-narrative review article. Iranian J Public Health. (2015) 44:1309.

47. Caspi CE, Sorensen G, Subramanian S, Kawachi I. The local food environment and diet: a systematic review. Health Place. (2012) 18:1172-87. doi: 10.1016/j.healthplace.2012.05.006

48. French SA, Story M, Jeffery RW. Environmental influences on eating and physical activity. Annual Review Public Health. (2001) 22:309-35. doi: 10.1146/annurev.publhealth.22.1.309

49. Glanz K, Sallis JF, Saelens BE, Frank LD. Healthy nutrition environments: concepts and measures. Am J Health Promotion. (2005) 19:330-3. doi: 10.4278/0890-1171-19.5.330

50. Dubé L, Du P, McRae C, Sharma N, Jayaraman S, Nie J-Y. Convergent innovation in food through big data and artificial intelligence for societalscale inclusive growth. Technol Innovation Manag Rev. (2018) 8:49-65. doi: 10.22215/timreview/1139

51. Dubé L, Labban A, Moubarac JC, Heslop G, Ma Y, Paquet C. A nutrition/health mindset on commercial big data and drivers of food demand in modern and traditional systems. Annals N Y Acad Sci. (2014) 1331:278-95. doi: 10.1111/nyas. 12595

52. Chandon P, Wansink B. Does food marketing need to make us fat? A review and solutions. Nutr Rev. (2012) 70:571-93. doi: $10.1111 / j .1753-4887.2012 .00518 . x$

53. Ruel MT, Minot N, Smith L. Patterns and Determinants of Fruit and Vegetable Consumption in Sub-Saharan Africa: A Multicountry Comparison: WHO Geneva (2005).

54. Ministry of Human Resource Development India nutrition profile. In: Development DoWaC, editor. New Delhi: Department of Women and Child Development (1998).

55. Jha SK, Pinsonneault A, Dubé L. The evolution of an ICT platform-enabled ecosystem for poverty alleviation: the case of eKutir. MIS Quarterly. (2016) 40:431-45. doi: 10.25300/MISQ/2016/40.2.08

56. World Health Organization. Fruit and Vegetables for Health: Report of the Joint FAO/WHO Workshop on Fruit and Vegetables for Health, 1-3 September 2004, Kobe, Japan. Geneva: World Health Organization (2005).

57. Balarajan Y, Selvaraj S, Subramanian SV. Health care and equity in India. Lancet. (2011) 377:505-15. doi: 10.1016/S0140-6736(10)61894-6

58. Faul F, Erdfelder E, Lang A-G, Buchner A. G* Power 3: a flexible statistical power analysis program for the social, behavioral, and biomedical sciences. Behav Res Methods. (2007) 39:175-91. doi: 10.3758/BF03193146

59. Pearce J, Hiscock R, Blakely T, Witten K. The contextual effects of neighbourhood access to supermarkets and convenience stores on individual fruit and vegetable consumption. J Epidemiol Community Health. (2008) 62:198-201. doi: 10.1136/jech.2006.059196

60. Kumar N, Harris J, Rawat R. If they grow it, will they eat and grow? Evidence from Zambia on agricultural diversity and child undernutrition. J Dev Stud. (2015) 51:1060-77. doi: 10.1080/00220388.2015.1018901

61. McDermott J, Johnson N, Kadiyala S, Kennedy G, Wyatt AJ. Agricultural research for nutrition outcomes-rethinking the agenda. Food Security. (2015) 7:593-607. doi: 10.1007/s12571-015-0462-9

62. Murty P, Rao MV, Bamji MS. Impact of enriching the diet of women and children through health and nutrition education, introduction of homestead gardens and backyard poultry in rural India. Agric Res. (2016) 5:210-7. doi: 10.1007/s40003-016-0206-x

63. Holben DH, McClincy MC, Holcomb JP, Dean KL, Walker CE. Food security status of households in Appalachian Ohio with children in Head Start. J Am Dietetic Asso. (2004) 104:238-41. doi: 10.1016/j.jada.2003.09.023

64. Gustafson A, Cavallo D, Paxton A. Linking homegrown and locally produced fruits and vegetables to improving access and intake in communities through 
policy and environmental change. J Am Dietetic Assoc. (2007) 107:584-5. doi: 10.1016/j.jada.2007.02.023

65. Dean WR, Sharkey JR. Rural and urban differences in the associations between characteristics of the community food environment and fruit and vegetable intake. J Nutr Educ Behav. (2011) 43:426-33. doi: 10.1016/j.jneb.2010.07.001

66. Thow AM, Verma G, Soni D, Soni D, Beri DK, Kumar P, et al. How can health, agriculture and economic policy actors work together to enhance the external food environment for fruit and vegetables? A qualitative policy analysis in India. Food Policy. (2018) 77:143-51. doi: 10.1016/j.foodpol.2018. 04.012

67. Parasuraman S, Rajaretnam T. Agriculture, food security and nutrition in Vidarbha: a household level analysis. Economic Political Weekly. (2011) 46:4250. Available online at: http://www.jstor.org/stable/41152371

68. Adhiguru P, Ramasamy C. Agricultural-Based Interventions for Sustainable Nutritional Security. Coimbatore: National Centre for Agricultural Economics and Policy Research and Tamil Nadu Agricultural University. (2003).

69. Glasson C, Chapman K, James E. Fruit and vegetables should be targeted separately in health promotion programmes: differences in consumption levels, barriers, knowledge and stages of readiness for change. Public Health Nutr. (2011) 14:694-701. doi: 10.1017/S1368980010001643

70. Padrão P, Laszczyńska O, Silva-Matos C, Damasceno A, Lunet N. Low fruit and vegetable consumption in Mozambique: results from a WHO STEPwise approach to chronic disease risk factor surveillance. Br J Nutr. (2012) 107:42835. doi: $10.1017 /$ S0007114511003023

71. Guillaumie L, Godin G, Vézina-Im L-A. Psychosocial determinants of fruit and vegetable intake in adult population: a systematic review. Int J Behav Nutr Phys Activity. (2010) 7:12. doi: 10.1186/1479-5868-7-12

72. Van Duyn MAS, Kristal AR, Dodd K, Campbell MK, Subar AF, Stables G, et al. Association of awareness, intrapersonal and interpersonal factors, and stage of dietary change with fruit and vegetable consumption: a national survey. Am J Health Promotion. (2001) 16:69-78. doi: 10.4278/0890-1171-1 6.2 .69

73. Pollard CM, Daly AM, Binns CW. Consumer perceptions of fruit and vegetables serving sizes. Public Health Nutr. (2009) 12:637-43. doi: $10.1017 / S 1368980008002607$
74. Paalanen L, Prättälä R, Palosuo H, Laatikainen T. Socio-economic differences in the consumption of vegetables, fruit and berries in Russian and Finnish Karelia: 1992-2007. Eur J Public Health. (2010) 21:35-42. doi: 10.1093/eurpub/ckp233

75. Kanungsukkasem U, Ng N, Van Minh H, Razzaque A, Ashraf A, Juvekar $S$, et al. Fruit and vegetable consumption in rural adults population in INDEPTH HDSS sites in Asia. Global Health Action. (2009) 2:1988. doi: $10.3402 /$ gha.v2i0.1988

76. Padilla L. Fruit consumption: dietary health and policy implications. Paper presented at 2001 Agricultural and Applied Economics Association Annual Meeting; 5-8 August 2001; Chicago, Illinois. (2001).

77. Dubé L, Fatemi H, Lu J, Hertzer C. The healthier the Tastier? Usa-india comparison studies on consumer Perception of a nutritious agricultural Product at Different Food Processing levels. Front Public Health. (2016) 4:6. doi: $10.3389 /$ fpubh.2016.00006

78. Rastogi S. Ayurvedic Science of Food and Nutrition. New York, NY: Springer (2014). doi: 10.1007/978-1-4614-9628-1

79. Plazibat I, Cejvanovic F, Vasiljevic Z. Analysis of fruit and vegetable value chains. Business Excellence. (2016) 10:169. Available online at: https://hrcak. srce.hr/170754

80. Padilla L, editor. Fruit consumption: dietary health and policy implications. Agricultural and Applied Economics Association Annual Meeting, Chicago, IL (2001).

Conflict of Interest: The authors declare that the research was conducted in the absence of any commercial or financial relationships that could be construed as a potential conflict of interest.

Copyright $\odot 2021$ Wu, Moore, McRae and Dubé. This is an open-access article distributed under the terms of the Creative Commons Attribution License (CC BY). The use, distribution or reproduction in other forums is permitted, provided the original author(s) and the copyright owner(s) are credited and that the original publication in this journal is cited, in accordance with accepted academic practice. No use, distribution or reproduction is permitted which does not comply with these terms. 